Research Article

\title{
Respiratory Rate Difference Before and After Pursed Lip Breathing Exercise on Asthma Patient in Pulmonary Polyclinic, TNI AU DR. M. Salamun Ban- dung Hospital
}

\author{
Arie Sulistiyawati ${ }^{*}{ }^{*}$, Ni Made Diah Pusparini Pendet 2 \\ ${ }^{1}$ Research STIKes Dharma Husada Bandung, Indonesia \\ ${ }^{2}$ Nursing Academy of Kesdam IX/Udayana, Indonesia
}

\section{Article history:}

Submission December 2019

Revised March 2020

Accepted March 2020

*Corresponding author:

E-mail:

Sulistiyawatiarie@gmail.com

\begin{abstract}
Introduction: Asthma is a reversible disease characterized by airway obstruction which tends to relapse due to certain factors. Asthma required adequate management to minimalize the frequently of the symptoms occurred and not become a burden for its sufferers. Pursed-Lip breathing (PLB) is an effective breathing technique used in managing asthma symptoms. This study aimed to know the difference in the respiratory rate (RR) before and after the PLB exercise on the asthma patients in Pulmonary Clinic, TNI AU dr. M Salamun Bandung Hospital. Method: A quasi-experimental study with a non-equivalent control group approach was used for this experiment. Of 106 asthma patients, 51 patients who met the inclusion criteria were chosen to participate in this study. The participants were asked to do a PLB exercise based on the standard operating procedure of PLB provided by the researcher. Results: The data analysis showed that there was a significant difference in the RR before and after the PLB exercise with an average of 23.90 and $19.94(p<0.05)$, respectively. Conclusions: This result indicated that PLB could affect the RR on asthma patients in Pulmonary Polyclinic, TNI AU dr. M Salamun Bandung Hospital.
\end{abstract}

Keywords: Asthma, respiratory rate, pursed lip breathing

\section{Introduction}

Asthma is a reversible disease characterized by airway obstruction which tends to relapse due to certain factors. A bronchial asthma attack usually happens as repeated paroxysmal expiratory dyspnea with wheezing and coughing caused by the bronchi muscle spasm, bronchi mucous inflammation, and purulent secret production. World Health Organization (WHO) stated that there are currently around 235 million asthma sufferers worldwide. There are around $80 \%$ of deaths caused by asthma attacks every year, with the highest number in low-moderate economies [1]. The prevalence of asthma continues to increase especially in developing countries due to lifestyle changes and increased air pollution. Based on the Indonesia of Health Research in
2013, the prevalence of asthma in Indonesia was $4.5 \%$ of the population, with a cumulative number of asthma cases around 11,179,032. Asthma affects disability and premature death especially in people aged 10-14 and 75-79 years. Beyond this age, early mortality is reduced, but it has more disability effects. Today, asthma is included in the 14 major diseases that cause disabilities throughout the world. However, it is important to be aware of asthma by increasing everyone's awareness to always know the right time to deal with respiratory diseases [2].

Asthma could cause some symptoms that could affect the productivity and quality of life of its survivor [3]. Acute exacerbation could occur at any time on short or long duration which would cause some hindrances on physi- 
cal and other daily activities in all aspects of life. Adequate and comprehensive management is required to control the symptoms.

The main goal of asthma management is to control the asthma symptom experienced by the patient and has fewer effects on their daily activities. Some asthma symptoms that usually happen are coughing, shortness of breath, wheezing sounds during an attack, discomfort feeling in the chest, and sleeping difficulty because of the coughing. Early management is important in preventing further damage to the lung tissues. Pharmacology and nonpharmacology therapy is an important part of this management.

Breathing therapy is one type of nonpharmacology approach to managing asthma symptoms. This therapy designed to strengthen the breathing muscle, improving oxygen circulation, controlling the symptom, and increasing quality of life. Breathing therapy is also effective in improving the breathing organ's function and managing the breathing pattern before or during an asthma attack [4].

Pulse Lip Breathing (PLB) is one of breathing therapy which effective in managing asthma symptoms. PLB is a technique done by holding air during the expiration period through the lip-puckering movement to make the expiration process getting slower. The lippuckering movement would make the lung deflating process happen perfectly. Complete gas exchange in the lungs would possibly happen through PLB. PLB also makes the breathing process more comfortable, able to set the lungs on the lower pressure, and keeping the airway open which would help the oxygenation carried well in the body. Adequate oxygenation could reduce the incidence of hyperventilation and hypoxia on asthma patients [5].

Several studies has shown that PLB helps to manage breathing difficulty in asthma patients. Visser et. al (2011) stated that PLB can increase intra-bronchi pressure during the expiration period and widen the bronchial diameter to make the efficient flow of inspiration and expiration during the breathing process[6]. A pilot study conducted showed that the nurses on Pulmonary Polyclinic of TNI AU dr. M Salamun hasn't implemented PLB properly on the asthma patients. The administration of nebulizer and bronchodilator agents was a common therapy chosen to manage asthma symptoms.

Sakhaei et al. suggested that patient with PLB training has a significant increase of the Saturation of Peripheral Oxygen (SPO2) index with the average difference of $2.05 \%$, Respiratory Rate (RR) of 0.65 minutes and Pulse Rate (PR) of $1.6 \mathrm{bpm}$, also an increasing number of systolic blood pressure index was found in healthy subjects (3.35 $\mathrm{mmHg}$ ) [7]. PLB as an inexpensive, easy, non-pharmacological, and non- invasive method, makes PLB considered as an important factor to improve physiologically and the status of oxygenation indicators in patients with pulmonary diseases [7].

This study aimed to know the respiratory rate (RR) difference before and after the Pursed Lip Breathing (PLB) exercise on asthma patients in Pulmonary Polyclinic, TNI AU dr. Salamun Bandung Hospital in 2018.

\section{Methods}

A quasi-experimental study with a nonequivalent control group approach as used for this study. From the population of 106 asthma patients who visited Pulmonary Polyclinic in TNI AU dr. M. Salamun Bandung, 51 patients (calculated with Slovin formula) who met the inclusion criteria were chosen to join this study. The inclusion criteria include a patient using asthma medication, did not have cardiovascular disease and neurologic disorder, while the exclusion criteria include no longer experiencing an asthma attack, did not follow the prescribed therapeutic regimen, and refused to participate. A t-test independent was used to know the difference of RR on the two groups. The t-test independent showed that if the sig value is $>0.05$, Ho would be accepted, while if the sig value is $<0.05$, Ho would be rejected. Our finding showed that the sig value was 0.00 $(<0.05)$, with the confidence level of $95 \%$, which means the Ho was rejected, indicated there was a significant difference in the RR before and after the PLB exercise.

\section{Results and Discussion}

The data analysis found that the average of RR on the 51 participants before and after the 
PLB exercise respectively was $23.90 \pm 1.95$ times and $19.94 \pm 1.26$ times. The mean difference was 3.96 with a $Z$ value of -6.199 and the $p$-value of 0.00 . Due to the $Z_{\text {value }}<Z_{\text {table }}=-1.96$ and sig. value was $<0.05$ on the confidence level of $95 \%$, the Ho was rejected. This statistical result indicated that PLB exercise affected the breathing pattern significantly.

Table 1 showed that the mean of the RR frequency before and after the exercise respectively were 23.90 and 19.94 with $\mathrm{p}=0.00$.

Table 1. RR Before and After Pursed Lip Breathing Exercise

\begin{tabular}{lcc}
\hline RR & Before & After \\
\hline Min & 20 & 16 \\
\hline Max & 28 & 22 \\
\hline Mean & 1,020833 & 0,856944 \\
\hline Std Dev. & 0,107639 & 01.26 \\
\hline $\mathbf{Z}$ & \multicolumn{3}{c}{-6.199} \\
\hline Sig & \multicolumn{2}{c}{0.000} \\
\hline Mean Diff. & \multicolumn{2}{c}{0,191666667} \\
\hline
\end{tabular}

After PLB exercise, the result shows a significantly different compared to before the exercise. Before and after PLB exercise data of respiratory rate means were 1.02 and 0.85 , respectively, showing that PLB exercise gives a $17 \%$ impact on respiratory rate. This study is in line with Sakhaei et al. study, where RR rate difference was reported in pre- and post-PLB exercise in the intervention group $(19.65 \pm 1.53)$. PLB helps asthma patients breathing comfortably [7]. PLB not only able to reducing dyspnea on asthma patients, but also helps to increase the peak of expiration flow, make the breathing process slower, reducing the exacerbation, pain level, and blood pressure.

Potdar also suggested that pursed-lip breathing is a better treatment for improving the expiratory flow rate compared to Breathing control in obstructive pulmonary disease patients [8], Because PLB keeps airways open by creating back pressure in the airways, and in turn will increase the tidal volume and reduces breathings process which causes an increase in the expiratory flow in COPD patients. This study is in line with previous experi- ments, where PLB induces a slower breathing pattern, fixing the oxygen transport, helping the patients control their breathing, strengthen the respiration muscle, and increasing the excitation of $\mathrm{CO} 2$ during the expiration period. The accumulation of $\mathrm{CO} 2$ could reduce the alveolus elasticity which could decrease the optimal gas exchange in the lungs. PLB can reduce $\mathrm{CO} 2$ accumulation and reduce all asthma symptoms, especially dyspnea as the most frequent complaint happened on asthma patients. The low frequency of dyspnea is an accurate indicator of successful asthma management.

PLB is relatively easy to do in any place, involved no complex movements, doesn't need any cost, and having no side effects. PLB also conducted in a relatively short time, which only needs 5 minutes [9]. Dechman and Wilson in their study entitled "Evidence Underlying Breathing Retraining in People with Stable Chronic Obstructive Pulmonary Disease" showed that PLB exercise was able to reduce the RR resistive pressure, constriction during expiration, and dyspnea on the asthma patient [10]. Karam et al. also stated that PLB is the easiest breathing exercise when compared with yoga pranayama and abdominal breathing [11].

\section{Conclusion}

Our finding showed that there was a significant difference in the RR before and after a pursed-lip breathing exercise on the asthma patient with an average difference of 3.96. We suggest to the health professionals, not only at TNI AU Dr. M Salamun Bandung Hospital but also in general, to implement PLB as an alternative non-pharmacological management therapy in managing the breathing pattern of the asthma patient.

\section{Acknowledgment}

Authors would like to thank all participants involved in this study for supporting and facilitating this research.

\section{References}

1. WHO (2019) Asthma https://www.who.int/news-room/q-adetail/asthma. 
2. Kementerian Kesehatan RI (2018) Asma Penting Diwaspadai (Never Too Early, Never Too Late)," http://yankes.kemkes.go.id/read-asma-pentingdiwaspadai-never-too-early-never-too-late-42 09.html.

3. Global Initiative for Asthma (2002) Pocket Guide for Asthma Management and Prevention: A Pocket Guide for Physicians and Nurses. National Institutes of Health, National Heart, Lung, and Blood Institute.

4. Nugroho S (2009) Terapi Pernapasan pada Penderita Asma," MEDIKORA, no. 1 .

5. Andrianty F, Adiputra N, Sugijanto (2017) Penambahan Pursed Lip Abdominal Breathing Pada Latihan Aerobik Lebih Baik Dalam Meningkatkan Kapasitas Fungsi Paru Penderita Asma Bronkial. Sport Fit. J. 5 (1): 42-51.

6. Visser FJ, Ramlal S, Dekhuijzen PNR, Heijdra YF (2011) Pursed-lips breathing improves inspiratory capacity in chronic obstructive pulmonary disease. Respiration 81 (5): 372-378.
7. Sakhaei S, Sadagheyani HE, Zinalpoor S, Markani A K, Motaarefi H (2018) The impact of pursed-lips breathing maneuver on cardiac, respiratory, and oxygenation parameters in COPD patients. Open Access Maced. J. Med. Sci. 6 (10): 1851.

8. Potdar S (2018) A Comparative Study between the Effect of Breathing Control and Pursed Lip-Breathing Exercises in COPD Patients on Expiratory Flow Rate. J. Physiother. Res. 2 (4): $1-3$

9. Smeltzer SC, Bare BG (2013) Buku Ajar Keperawatan Medikal-Bedah.

10. Dechman G, Wilson CR (2004) Evidence underlying breathing retraining in people with stable chronic obstructive pulmonary disease. Phys. Ther. 84 (12): 11891197.

11. Karam M, Kaur BP, Baptist AP (2017) A modified breathing exercise program for asthma is easy to perform and effective. J. Asthma 54 (2): 217-222. 